\title{
Neutron Spin-Echo Study of the Dynamic Behavior of Amphiphilic Diblock Copolymer Micelles in Aqueous Solution
}

\author{
Hideki Matsuoka, Yusuke Yamamoto, Minoru Nakano, Hitoshi Endo, and \\ Hitoshi Yamaoka*,†
}

Department of Polymer Chemistry, Kyoto University, Kyoto 606-8501, J apan

Reiner Zorn, Michael Monkenbusch, and Dieter Richter

Institute für Festkörperforschungs, Forschungszentrum J ülich GmbH,

D-52425 J ülich, Germany

Hideki Seto and Youhei Kawabata

FIAS, Hiroshima University, Higashi-Hiroshima, Hiroshima 739-8521, J apan

Michihiro Nagao

Neutron Scattering Laboratory, Institute of Solid State Physics, The University of Tokyo, Tokai, I baraki 319-1106, J apan

Received November 29, 1999. In Final Form: September 5, 2000

\begin{abstract}
We examined the dynamics of amphiphilic polymer micelles of the diblock copolymer HOVE-NBVE (hydroxyethylvinyl ether as a hydrophilic segment and n-butylvinyl ether as a hydrophobic segment) in aqueous solution using the neutron spin-echo (NSE) technique. The time-correlation function obtained for the polymer micelles was well fitted by double exponential function, and the fast and slow modes could beestimated separately. Theslow mode was dominant at smaller scattering angles, and showed an excellent linearity in $\Gamma$ (decay rate) vs $q^{2}$ (scattering vector) plot. The diffusion coefficient evaluated from its slope and the hydrodynamic radius, $R_{h}$, by the Einstein-Stoke equation were consistent with the size of the polymer micellethat was estimated by small-angleneutron scattering (SANS), small-angleX-ray scattering (SAXS), and dynamic light scattering (DLS). Hence, this slow mode reflects the translational diffusion of the polymer micelle in aqueous solution. The fast mode, which was 1 order of magnitude faster than the slow mode, was a major factor for larger scattering angle regions in which the SANS curve showed blob scattering. Thus, the fast mode appears to bean internal motion of the polymer micelle, like the breathing mode of the hydrophilic shell (corona) around the polymer micelle.
\end{abstract}

\section{Introduction}

Amphiphilic polymers, sometimes called polymer surfactants, are a class of macromolecules that consist of hydrophobic and hydrophilic segments connected by a covalent bond. The coexistence of these two kinds of segments in a single polymer chain is expected to produce very interesting characteristics, such as surface activity, and micellization. In the $1950 \mathrm{~s},{ }^{1}$ the possi bility of micelle formation by block copolymers in selective solvents was pointed out, and in 1964, Krause discovered micelle formation in fractionated samples of a methyl methacrylate-styrene-methyl methacrylate triblock copolymer in solution by systematic light scattering (LS) and viscosity measurements. ${ }^{2} \mathrm{~A}$ larger mol ecular weight characteristic of micel les was obtained by LS both for solutions in acetone (a nonsolvent for polystyrene) and triethylbenzene (a nonsolvent for polymethymethacrylate). More recently, micelle formation by di- and triblock copolymers in selective solvents has been reported. ${ }^{3-10}$ Recently, it has

\footnotetext{
* To whom correspondence should be addressed.

† Present address: Department of Materials Science, U niversity of Shiga Prefecture, Hassaka-cho, Hikone, Shiga 522-8533, J apan.

(1) Marrett, E. M. J . Polym. Sci. 1967, 24, 467.

(2) Krause, S. J . Phys. Chem. 1964, 68, 1948.
}

become possible to synthesize diblock copolymers whose segment length is precisely controlled by living cationic polymerization ${ }^{11}$ by the development of synthetic techniques, which give us quantitative information on the micellization mechanism. However, most of the previous polymer micellestudies were for organic sol vent systems, and aqueous studies had been limited to so-called Pluronic systems, such as poly(ethylene oxide)(PEO)/poly(propylene oxide) (PPO) and PEO/poly(butylene oxide) (PBO), which are commercially available. A few investigators have reported studies on the micellization for other aqueous

(3) Riess, G. In Encyclopedia of Polymer Science and Engineering; 2nd ed., J ohn Wiley: NY, 1985; Vol. 2, p 324. 31.

(4) Halperin, A.; Tirrel, M.; Lodge, T. P. Adv. Polym. Sci. 1992, 100,

(5) Tuzar, Z;; Kratochvil, P. In Surfaces and Colloid Science; Matijevic', E., Ed.; Plenum Press: New York, 1993; Vol. 15, p 1.

(6) Hilfiker, R.; Chu, B.: Xu, Z. J . Colloid Interface Sci. 1989, 133, 176. Hilfiker, R.; Wu, D. Q.; Chu, B. J . Colloid InterfaceSci 1990, 135, 573.

(7) Gao, Z.; Zhong, X.-F.; Eisenberg, A. Polym. Prepr. 1994, 35, 570

(8) Antonetti, M.; Heintz, S.; Schmidt, M.; Rosenauer, C. Macromolecules 1994, 27, 3276.

(9) Munch, M. R.; Gast, A. P. Macromol ecules 1988, 211360.

(10) Qin, A.;Tian, M.; Ramireddy, C.; Webber, S. E.; Munk, P.; Tuzar, Z. Macromol ecules 1994, 27, 120.

(11) Minoda, M; Sawamoto, M; Higashimura, T. Macromolecules 1987, 20, 2045. 
Table 1. Characteristics of Block Copolymer Used and Their Micelles in Aqueous Solution

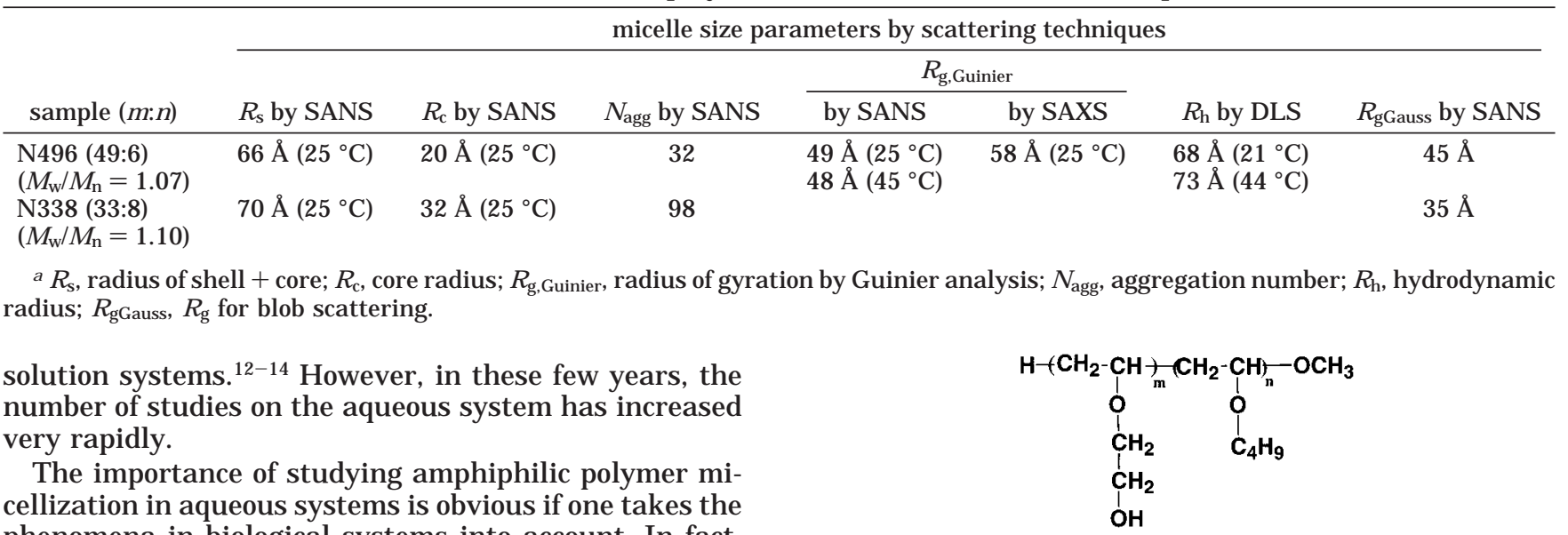
phenomena in biological systems into account. In fact, the number of studies on aqueous systems has recently increased and interesting phenomena have been found. For example, Nakano et al. ${ }^{15}$ performed a systematicsmallangle X-ray scattering (SAXS) and small-angle neutron scattering (SANS) study on diblock amphiphilic copolymers of vinyl ether in aqueous solution. They evaluated thewhol eshapeand detail ed internal structure of polymer micelles as a function of the hydrophobic chain length (i.e., hydrophobicity), and found a sphere-rod transition of micelle geometry. They observed the coexistence of rodlike micelles and spherical micelles. They also performed a systematic SAXS study for amphiphilic polymer micelles having an octadecyl chain as a hydrophobic segment as a function of solution temperature. ${ }^{16}$ They found a disklike micelle at l ower temperatures, whereas a spherical micelle was observed at higher temperature. Theseobservations suggest that the melting temperature of the hydrophobic core has an important role in the morphology of polymer micelles. Various novel amphiphilic block copolymers containing silicon, fluorine, etc. have been synthesized and their association behavior, mi cellar structure and its transition, and unique characters such as specific solubilization of hydrophobic molecules, have been reported. ${ }^{17-20}$

As mentioned above, structural studies on micelle geometry in aqueous media are now being systematically performed by several researchers. Our next interest is the dynamics of micelle structure. For nonaqueous systems, studies have been performed by using theneutron spin-echo (NSE) technique. NSE was established by the pioneering work by Mezei. ${ }^{21,22}$ NSE can detect quasielastic and inelastic scattering from the system, from which a dynamic character of the system can be evaluated. A famous example of the application of NSE to polymer

(12) Xu, R.; Winnik, M. A.; Hallett, F. R.; Riess, G.; Croucher, M. D. Macromolecules 1991, 24, 87.

(13) Zhu, J .; Lennox, B.; Eisenberg, A.J .Phys. Chem. 1992, 96, 4727

(14) Kriz, J.; Plestil, J .; Tuzar, Z.; Pospisil, H.; Brusm J .; J akes, J .:

Masar, B.: Vlcek, P.: Doskocilova, D. Macromolecules 1999, 32, 397.

(15) Nakano, M.; Matsuoka, H.; Yamaoka, H.; Poppe, A.; Richter D. Macromolecules 1999, 32, 697.

(16) Nakano, M.; Matsumoto, K.: Matsuoka, H.; Yamaoka, H. Macromolecules 1999, 32, 4029.

(17) Matsumoto, K.; Miyagawa, K.; Matsuoka, H.; Yamaoka, H. Polym. J. 1999, 31, 609.

(18) Nakano, M.; Deguchi, M.; Matsumoto, K.; Matsuoka, H.; Yamaoka, H. Macromolecules 1999, 32, 7437.

(19) Nakano, M.; Deguchi, M.; Endo, H.; Matsumoto, K.; Matsuoka, H.; Yamaoka, H. Macromolecules 1999, 32, 6088.

(20) Matsumoto, K.; Kubota, M.; Matsuoka, H.; Yamaoka, H. Macromol ecules 1999, 32, 7122.

(21) Mezei, F. Z. Phys. 1972, 225, 146.

(22) Mezei, F. Neutron Spin-Echo; Springer Verlag: NY, 1980. Ewen, B.; Richter, D. Adv. Polym. Sci. 1997, 134, 1.

Figure 1. Structure of amphiphilic diblock copolymer used in this study.

systems is the important work by Richter et al.23,24 who observed the reptation motion in polymer melts. Later, Farago et al. ${ }^{25 a, b}$ and Takeda et al..$^{25 c}$ performed systematical and extensive NSE works on the deformation of microemulsion droplets. Because the NSE technique provides information on the dynamics in the length scale of polymers and polymer assemblies, this techniqueshould be useful for studying the dynamics of polymer micelles. Dynamic light scattering (DLS) is now generally used to evaluate the dynamics in the system, but the dimension of the structure of the system is limited to a large region because of the limitation of $q$ (the scattering vector: $q=$ $4 \pi \mathrm{n} \sin \theta / \lambda, 2 \theta$ is the scattering angle, $\lambda$ is the wavelength of neutron, $\mathrm{X}$-ray, and laser light, $\mathrm{n}$ is the refractive index of the medium) range covered. In fact, some NSE studies on polymer micelles in nonaqueous media have been reported, ${ }^{26}$ and NSE should be useful to examine the dynamics of the hydrophilic shell (corona) around the polymer micelle.

Here, we performed a systematic NSE study for di bl ock copolymer micelles in aqueous solution to estimate the dynamic properties of this system.

\section{Experimental Section}

a. Samples. The polymer sampleused was a di block copol ymer of hydroxyethylvinyl ether as a hydrophilic segment and nbutylvinyl ether as a hydrophobic segment (HOVE-NBVE). (Figure 1). We denotethedegree of polymerization of hydrophilic and hydrophobic segments by mand n, respectively. Twosamples, one with an $\mathrm{m}: \mathrm{n}=49: 6$ (N496) and another with that of 33:8 (N338) were used. The polydispersity index $\left(M_{w} / M_{n}\right)$ by gel permeation chromatography beforehydrolysis was 1.07 and 1.10 , respectively. These copolymers were synthesized in our laboratory. Complete details of the procedure of synthesis appear elsewhere. ${ }^{15}$ The characteristic properties of the polymers used are summarized in Table 1 . The diblock copolymer synthesized was purified by dialysis against Milli-Q water and then lyo-

(23) Richter, D.; Ewen, B.; Farago, B.; Wagner, T. Phys. Rev. Lett. 1989, 62, 2140

(24) Richter, D.; Farago, B.; Fetters, L. J .; Huang, J . S.; Ewen, B.; Lartigue, C. Phys. Rev. Lett. 1990, 64, 1389.

(25) (a) Huang, J . S.; Milner, S. T.; Farago, B.; Richter, D. Phys. Rev. Lett. 1987, 59, 2600, (b) Farago, B.; Richter, D.; Huang, J . S.; Safran, S. A.; Milner, S. T. Phys. Rev. Lett. 1990, 65, 3348, (c) Takeda, T.; Komura, S.; Seto, H.; Nagai, M.; Kobayashi, H.; Yokoi, E.; Ebisawa, T.; Tasaki, S.; Zeyen, C. M. E.; Takahashi, S.; Yoshizawa, H. Physica B 1995, 213\&214, 863. (d) Takeda, T.; Kawabata, Y.; Seto, H.; Ghosh, S. K. Okuhara, D.; Komura, S.; Nagao, M.; Brulet, A.; Teixeira, J . J . Phys. Chem. Sol. 1999, 60, 1375.

(26) Farago, B.; Monkenbusch, M.; Richter, D.; Huang, J . S.; Fetters, L. J .; Gast, A. P. Phys. Rev. Lett. 1993, 71, 1015. 
(a)

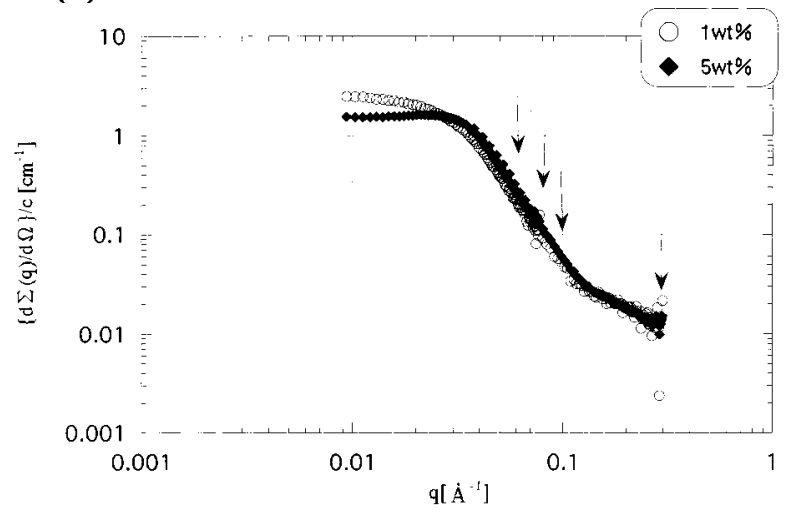

(b)

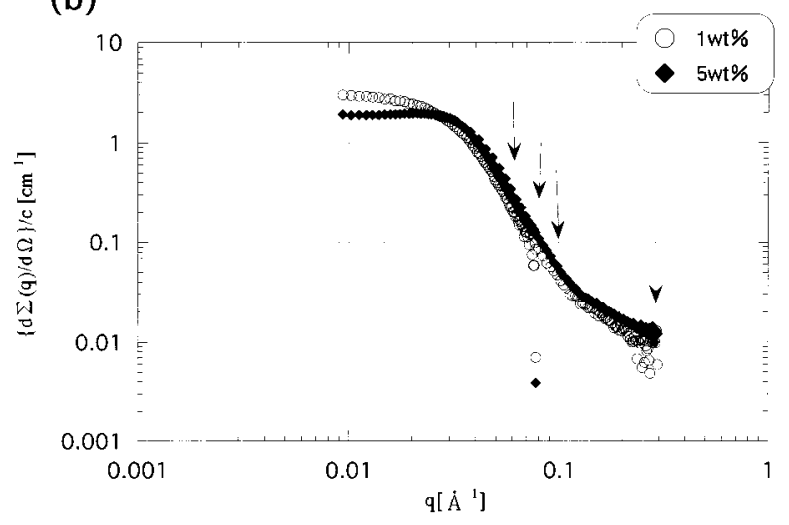

(c)

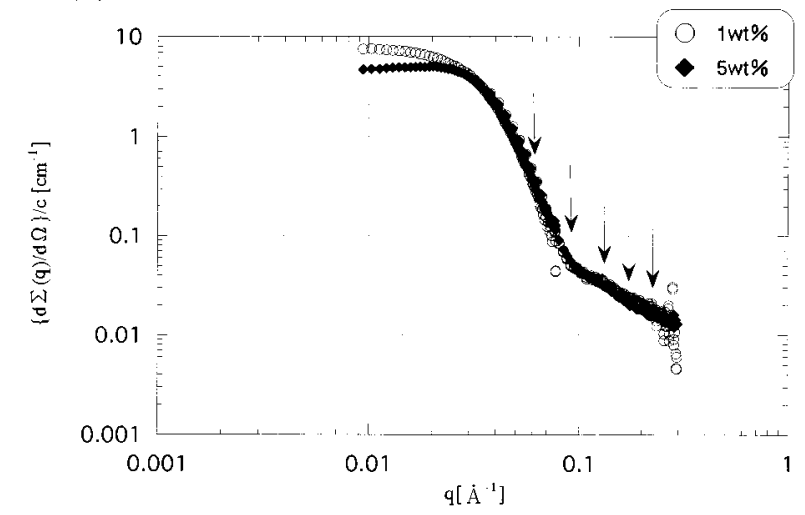

Figure 2. SANS profiles for $\mathrm{N} 496$ in 1 wt $\%$ and 5 wt $\% D_{2} \mathrm{O}$ solutions at $21^{\circ} \mathrm{C}$ (a) and $45^{\circ} \mathrm{C}$ (b), and for $\mathrm{N} 338$ in 1 wt $\%$ and 5 wt $\% \mathrm{D}_{2} \mathrm{O}$ solutions at $25^{\circ} \mathrm{C}$ (c).

philized. The solution samples were prepared by dissolving a suitable amount of polymer into deuterium hydroxide (Aldrich, D:99.98 at. \%) as the solvent.

b. NSE Instruments and Experiments. NSE experiments for the N 496 sample were performed using the NSE instrument at J RR-3M, Tokai, J apan which was constructed by Takeda et al. The details of this instrument have been fully described elsewhere. ${ }^{25,27} \mathrm{~A}$ specially designed quartz cell was used. The sample thickness was $5 \mathrm{~mm}$. NSE experiments for N338 were performed at Forschungszentrum J ülich, Germany, for which details can be found elsewhere. ${ }^{28}$ The sampl esol utions were put into a rectangular quartz cell. The accumulation time ranged

(27) (a) Takeda, T.; Seto, H.; Komura, S.; Ghosh, S. K.; Nagao, M.; Matsuba, J.; Kobayashi, H; Ebisawa, T.; Tasaki, S.; Zeyen, C. M. E.; I to, Y; Takahashi, T.; Yoshizawa, H.J . Phys. Soc. J pn., Suppl. A 1996, 65, 189. (b) Takeda, T.; Seto, H.; Kawabata, Y.; Okuhara, D.; Krist, T.; Zeyen, C. M. E.; Anderson, I. S.; Hoeghoej, P.; Nagao, M.; Ýoshizawa, H.; Komura, S.; Ebisawa, T.; Tasaki, S. J . Phys. Chem. Sol. 1999, 60, 1599. (a)

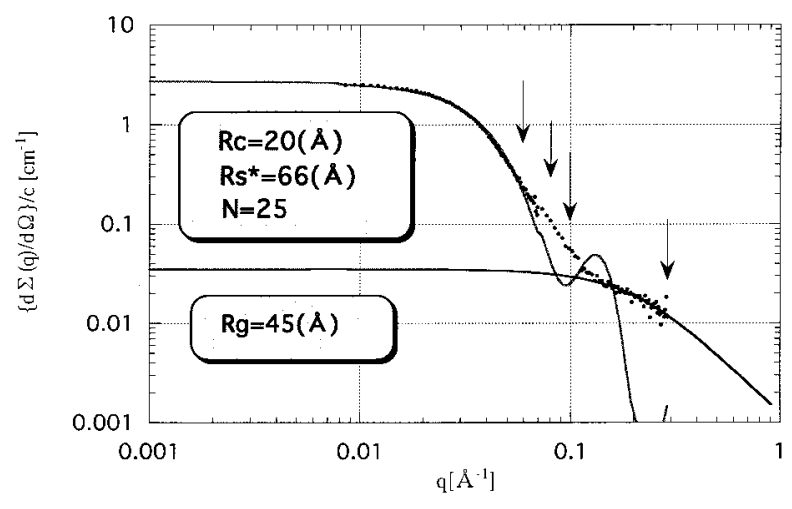

(b)

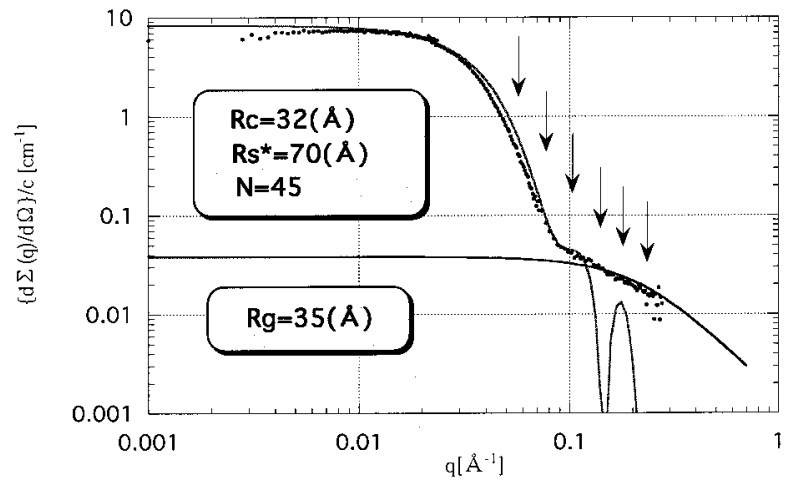

Figure 3. Model fitting of SANS profiles for N496 (a) and $\mathrm{N} 338$ (b) in 1 wt $\% \mathrm{D}_{2} \mathrm{O}$ solutions at $25^{\circ} \mathrm{C}$. The dots are the experimental data, the gray line (upper line in the small q region and with peak in large q region) was obtained by the core-shell spherical model. $R_{c}$ is the coreradius, $R_{s}$ is theradius of core + shell, and $\mathrm{N}$ is the aggregation number $\left(\mathrm{N}_{\text {agg }}\right.$ in Table 1). The black line (lower curve in the low q region which shows monotonical decrease) is the fitting curve for a higher q region ( $q>0.1$ ) by Debye function for the scattering from Gaussian coil. $R_{g}$ is the radius of gyration of the coil ( $R_{g \text { Gauss }}$ in Table 1$)$.

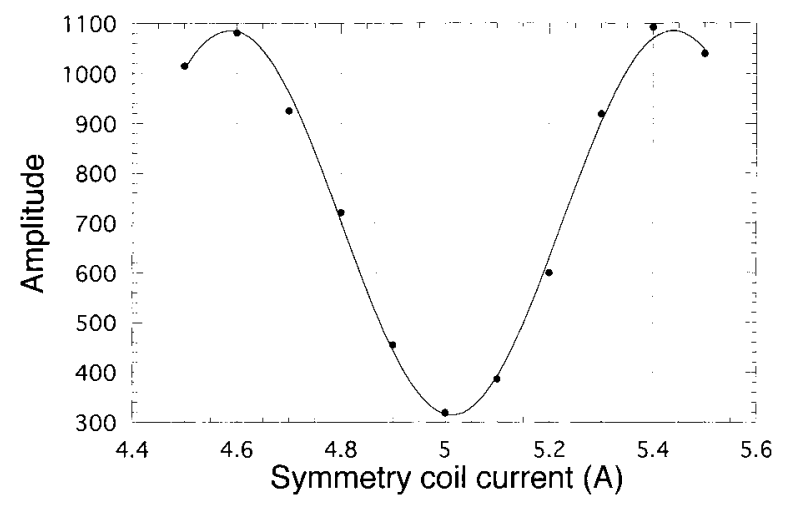

Figure 4. Typical example of echosignal at $21^{\circ} \mathrm{C}$ for $5 \% \mathrm{~N} 496$; where $q$ is $0.06 \AA^{-1}$.

from 6600 to 82500 s depending on the sample and instrument. The temperature of the sample was controlled by circulating thermostated water for both instruments. Grafoil was used to measure the resolution function of the spectrometers.

c. SANS Experiments. To check the size and shape of the micelle in heavy water and also its change by temperature, the SANS measurements were performed using the SANS-U beam line of ISSP, University of Tokyo, at J RR-3M, Tokai. ${ }^{29}$ Experimental conditions and methods wereas described previously. ${ }^{15,16}$

(28) Monkenbusch, M.; Schätzler, R.; Richter, D. Nucl. Instrum. Methods Phys. Res. 1997, A399, 301.

(29) Ito, Y.; Imai, M.; Takahashi, S. Physica B 1995, 213, 214, 889. 

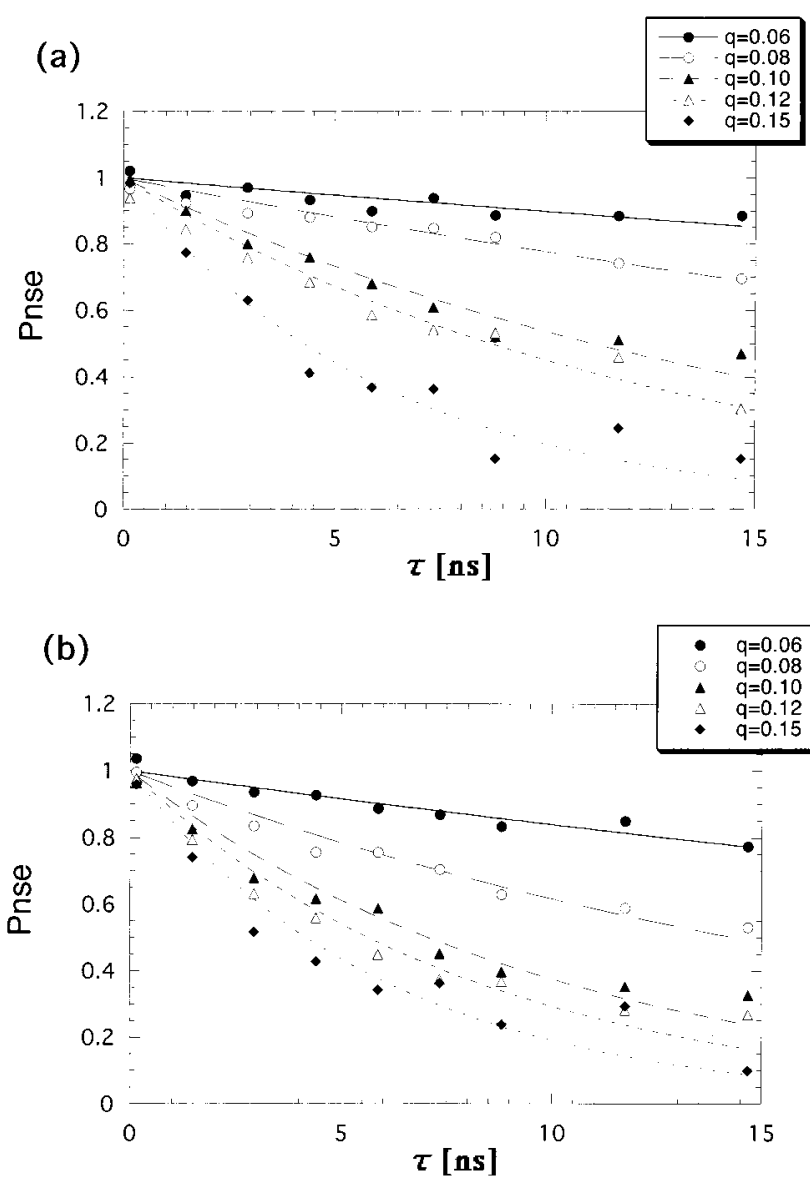

Figure 5. Thetimecorrelation function obtained by NSE ( $\left.P_{\text {nse }}\right)$ for $\mathrm{N} 496$ micelles in $5 \% \mathrm{D}_{2} \mathrm{O}$ solution at $21^{\circ} \mathrm{C}(\mathrm{a})$ and $45^{\circ} \mathrm{C}$ (b). The solid and dotted lines show the best-fit curves obtained by single-exponential fitting.

d. DLS Experiments. We performed DLS experiments to estimatethetranslational diffusion coefficient of polymer micelle independently, using a combi nation of $\mathrm{BI}-30$ goniometer and $\mathrm{BI}$ 9000 correlator (Brookhaven, Ronkonkoma, NY). Details of this instrument and measurement procedures appear el sewhere. ${ }^{30,31}$ Wealso used $\mathrm{a}_{2} \mathrm{O}$ solution to match theexperimental condition of NSE. Themeasurements were performed at scattering angles of 60,90 , and 120 degrees. Theobtained timecorrelation function of scattering intensity was converted to the correlation function for thescattered field $\mathrm{g}^{(1)}(\mathrm{q}, \tau)$ by utilization of the Siegert rel ation. The $\mathrm{g}^{(1)}(\mathrm{q}, \tau)$ functions were analyzed by the cumulant fitting to evaluatethe decay rate $\Gamma$. To estimate the hydrodynamicradius, we used the Stokes-Einstein equation.

e. SAXS Experiments. We performed the small-angleX-ray scattering (SAXS) experiments to estimatetheradius of gyration $\left(R_{g}\right)$ of polymer micelles independently by using an instrument in our laboratory as described el sewhere. 32 The sample cell was a 2-mm $\phi$ glass capillary (Mark, Germany). The accumulation time was 5000-10000 s. The scattering from the solvent was measured independently and subtracted from the solution. The data thus obtained were corrected for sensitivity of 1D-PSD (position sensitive detector) and then desmeared.

\section{Results and Discussion}

a. The Size and Shape of Polymer Micelle. Figures $2 a$ and $2 b$ show the SANS profile for N 496 in $1 \%$ and $5 \%$ $\mathrm{D}_{2} \mathrm{O}$ solutions at $21{ }^{\circ} \mathrm{C}$ and $45^{\circ} \mathrm{C}$, respectively. At both

(30) Matsuoka, H.; Morikawa, H.; Yamaoka, H. Colloids Surf. A 1995, 109, 137.

(31) Matsuoka, H.; Ogura, Y.; Yamaoka, H. J . Chem. Phys. 1998, $109,6125$.

(32) Ise, N.; Okubo, T.; Kunugi, S.; Matsuoka, H.; Yamamoto, K.; Ishii, Y. J . Chem. Phys. 1984, 81, 3294.

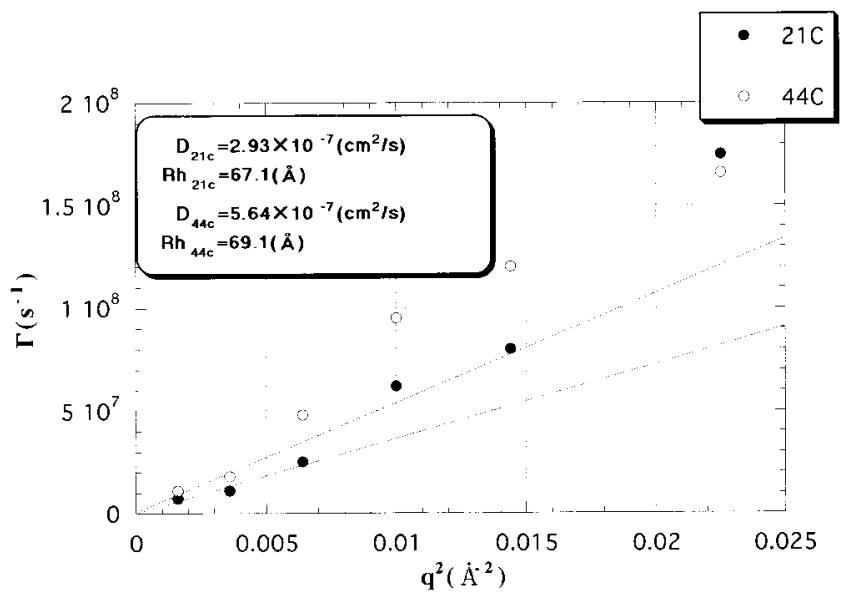

Figure 6. $\Gamma$ vs $\mathrm{q}^{2}$ plot for the single-exponential fitting result for N496.
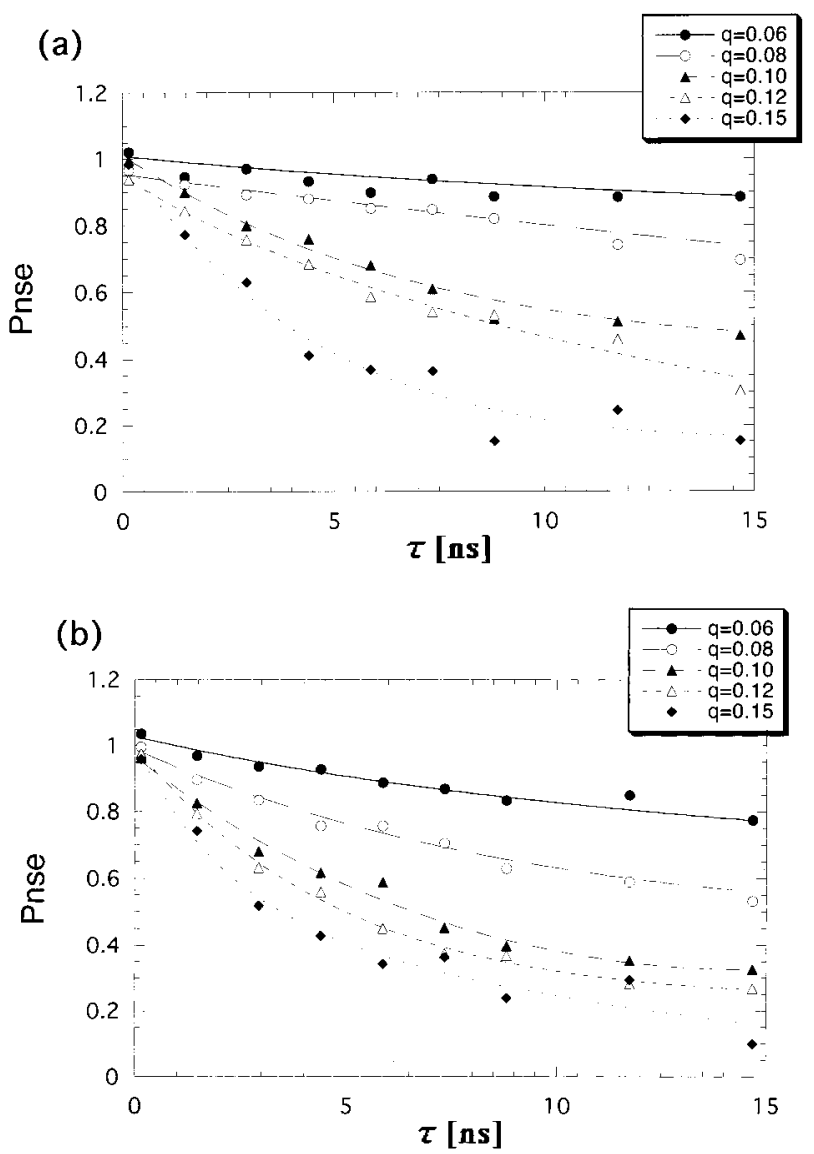

Figure 7. Thetimecorrelation function obtained by NSE ( $\left.P_{\text {nse }}\right)$ for $\mathrm{N} 496$ micelles in $5 \% \mathrm{D}_{2} \mathrm{O}$ solution at (a) $21^{\circ} \mathrm{C}$ and (b) $45^{\circ} \mathrm{C}$. The solid and dotted lines show the best-fit curves obtained by double-exponential fitting.

temperatures, only a slight difference was observed between 1 and $5 \%$ in very small angle regions. This can be attributed to the slight intensity decrease by interparticleinterferenceat a higher concentration, $5 \%$. Hence, there was no effect of the concentration in this concentration range. By Guinier analysis ${ }^{33}$ for a $1 \%$ solution, the

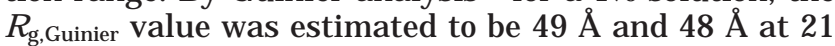
${ }^{\circ} \mathrm{C}$ and $45^{\circ} \mathrm{C}$, respectively, that is, unaffected by the temperature in this temperature range. By SAXS measure-

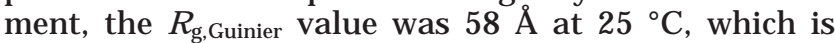

(33) Guinier, A.: Fournet, G. Small-angle Scattering of X-rays; Wiley: NY, 1955. 


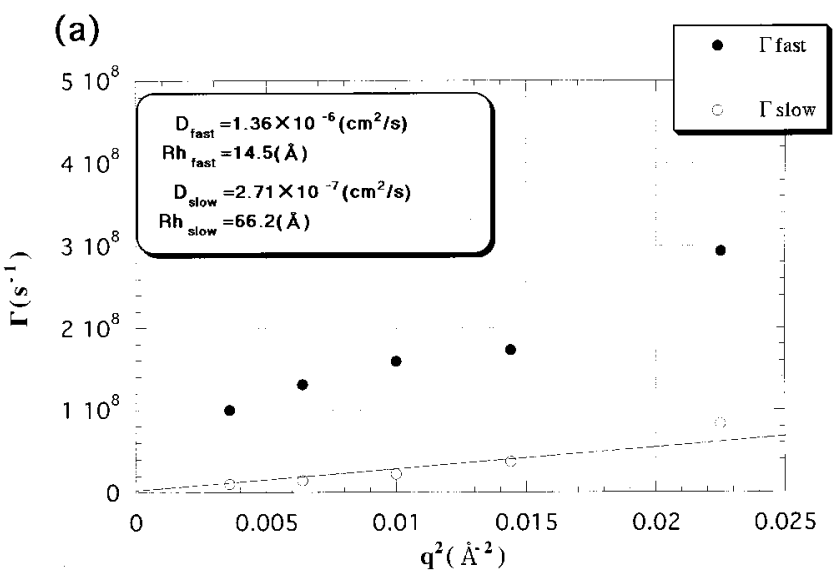

(b)

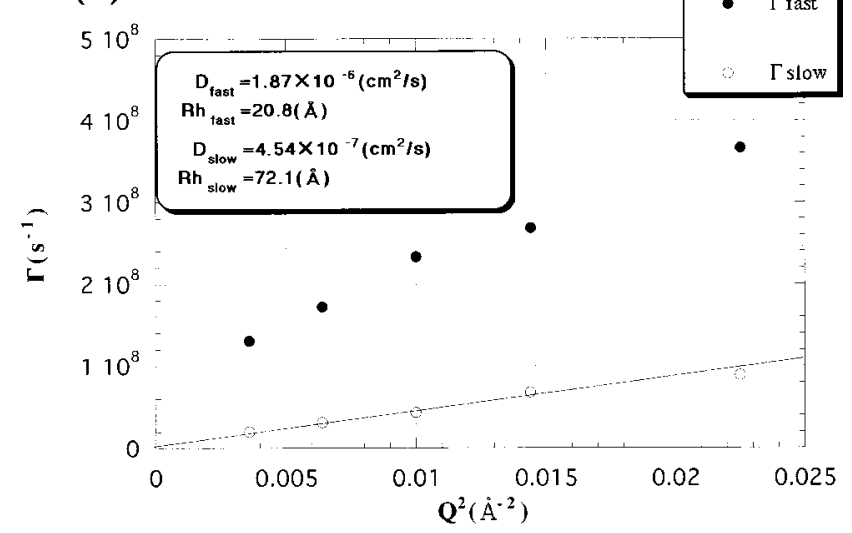

Figure 8. $\Gamma$ vs $\mathrm{q}^{2}$ plot for the double-exponential fitting result for $\mathrm{N} 496$ at (a) $21^{\circ} \mathrm{C}$ and (b) $45{ }^{\circ} \mathrm{C}$.

reasonable if the difference of density profiles for el ectron and scattering length is considered. By the basicscattering theory, ${ }^{34}$ for a homogeneous particle, in which theel ectron/ scattering length density is constant, the same $R_{g}$ value should be obtained by SANS and SAXS. However, in this case the particleis not homogeneous but has a core-shell structure. Hence, the electron density profile is different from the scattering length density profile for the particle, which results in a different $R_{g, \text { Guinier }}$ value. Of course, the particle should have its own peculiar $R_{g}$ value depending on its size and structure, the observation of apparently different $R_{g, \text { Guinier }}$ values by SANS and SAXS here means that the particle has inhomogeneous inner structure, i.e., the core-shell structure in this case. NSE experiments were performed at $5 \%$ both at $21{ }^{\circ} \mathrm{C}$ and $45{ }^{\circ} \mathrm{C}$. The scattering angles, at which NSE experiments were performed, are shown by arrows in Figure 2. Figure 2c shows the SANS profile for N338 micelle in $\mathrm{D}_{2} \mathrm{O}$. Figure 3 shows themodel fitting results for both of thesemicelles. We used the spherical core-shell model and evaluated the coreradius $\left(R_{c}\right)$, the whole mi celle size (the sum of the core radius and shell thickness), $R_{s}$, and the aggregation number $\left(\mathrm{N}_{\text {agg }}\right)$. In this procedure, we used density values of 1.490 and $0.9483 \mathrm{~g} / \mathrm{cm}^{3}$ for HOVE and NBVE, respectively, which were determined in our previous SANS experiments by the contrast variation technique. ${ }^{15}$ The results are summarized in Table 1 . Reflecting a longer hydrophilic chain ( $\mathrm{m}$ value) for $\mathrm{N} 496$ sample, a smaller $\mathrm{N}_{\text {agg }}$ value was obtained. The $\mathrm{N}_{\text {agg }}$ value was calculated from the core volume and volume of a hydrophobic chain with length $\mathrm{n}$. As shown in Figure 3 , the core-shell fitting

(34) Higgins, J . S.; Benoit, H. Polymers and Neutron Scattering; Oxford, University Press: NY, 1994.
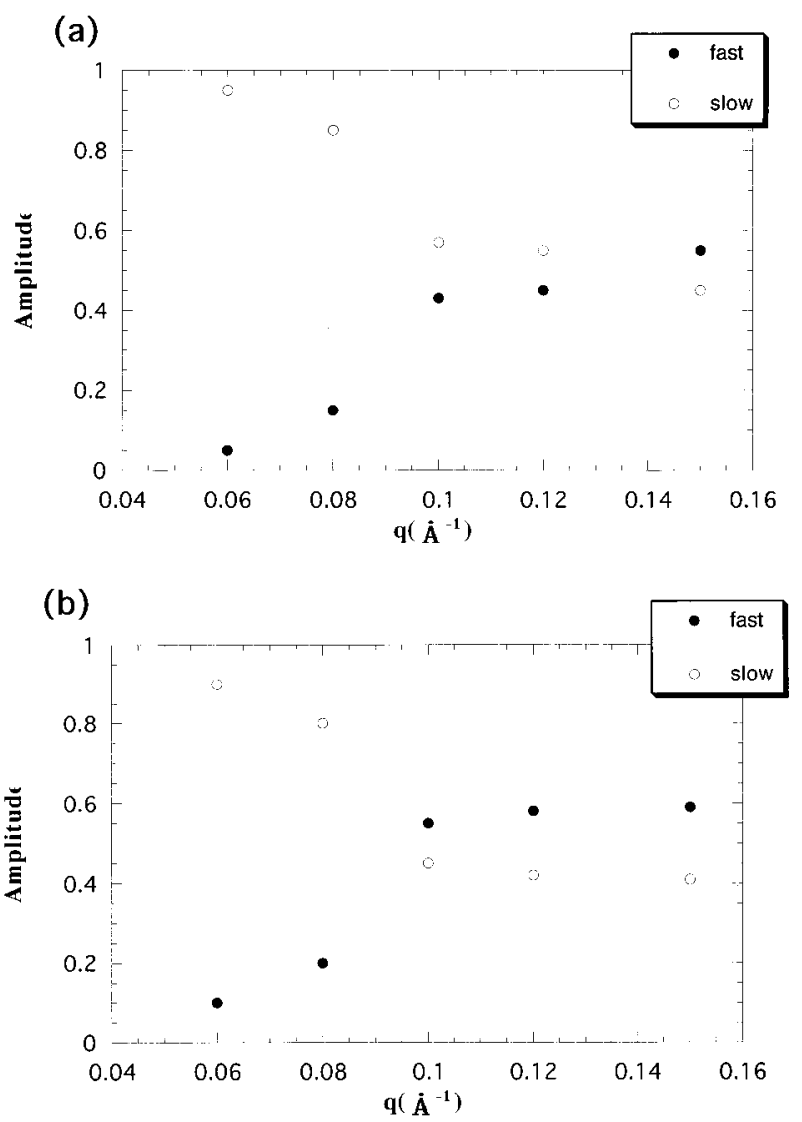

Figure 9. The $q$ dependence of the amplitudes for the fast $\left(A_{\text {fast }}\right)$ and slow $\left(A_{\text {slow }}\right)$ modes for $\mathrm{N} 496$ at (a) $21^{\circ} \mathrm{C}$ and (b) 45 ${ }^{\circ} \mathrm{C}$.

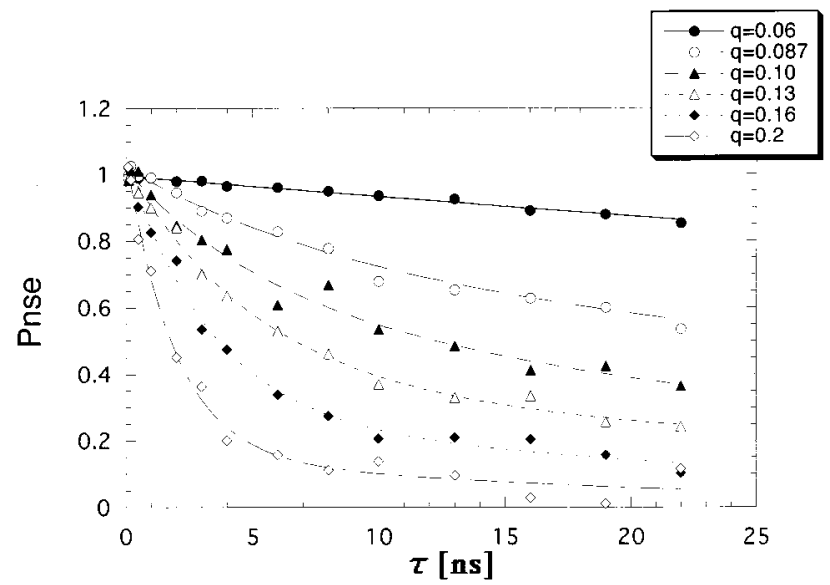

Figure 10. The time correlation function obtained by NSE $\left(P_{\text {nse }}\right)$ for $\mathrm{N} 338$ micelles in a $5 \%$ aqueous solution at $25^{\circ} \mathrm{C}$. The solid and dotted lines arethe best-fit curves obtained by doubleexponential function.

showed a satisfactory agreement with the experimental profile considering the fact that we used a simple coreshell model without polydispersity effect. For $N 496, R_{s}=$ $66 \AA$ was found, whereas $R_{g, \text { Guinier was }} 49 \AA$ by SANS. F or a homogeneous isolated sphere, it is well-known that the relation between $R$ (real sphere radius) and $R_{g}$ is $R=$ $(5 / 3)^{1 / 2} R_{g}$. By applying this relation to $R_{q}=49 \AA$, we find $R=63 \AA$, which is close to $R_{s}$ value, $66 \AA$. This fact may mean that the core-shell nature is not so remarkable for neutrons, different from X-ray case $\left(R_{g}=58 \AA\right)$, which is reasonable and consistent with the difference between the el ectron density profile (for X-ray) and the scattering length density profile (for neutron). On the other hand, 
(a)

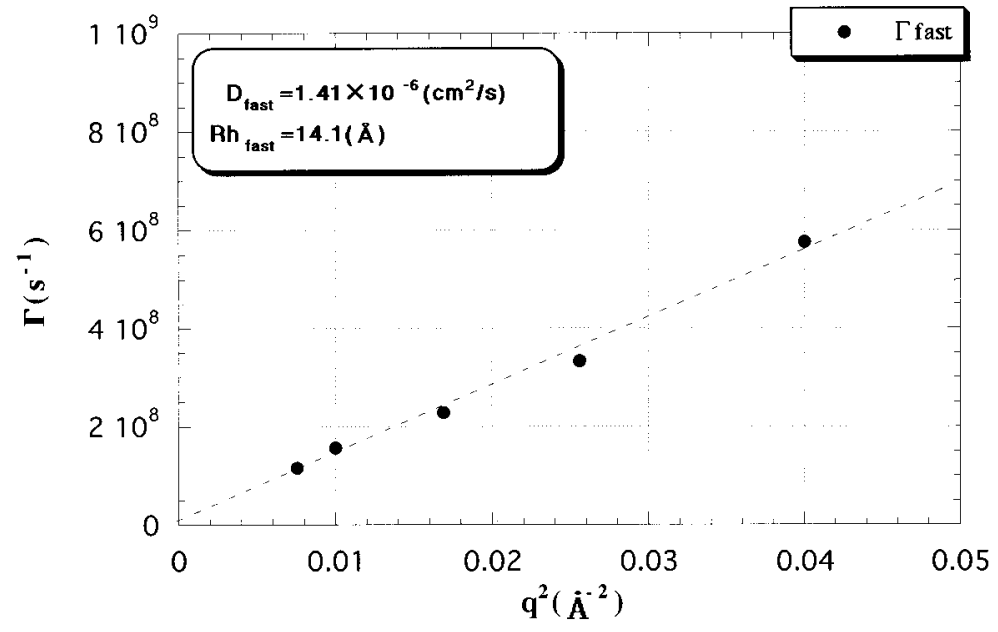

(b)

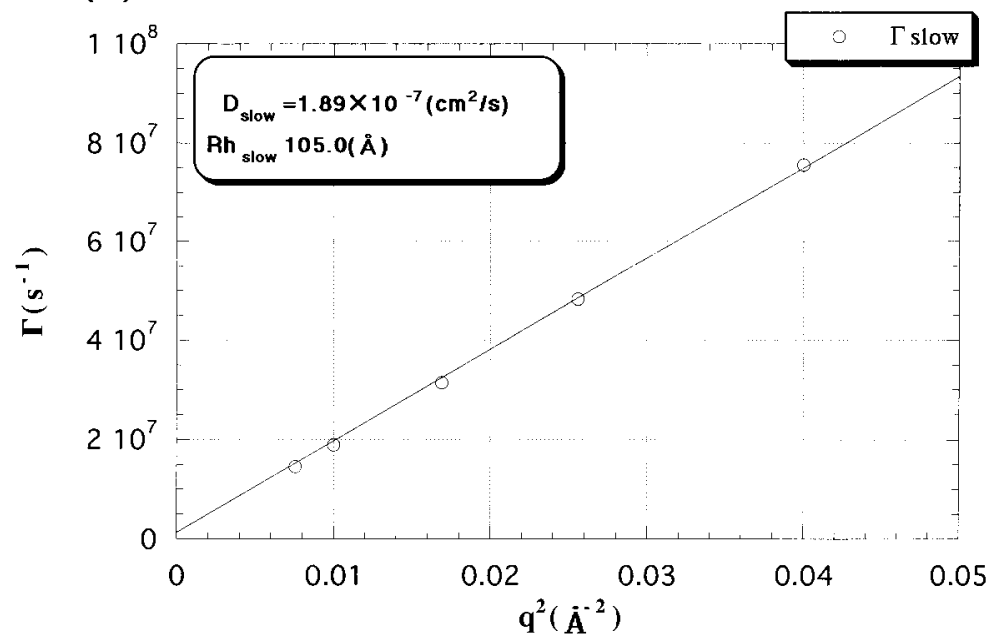

Figure 11. $\Gamma$ vs $q^{2}$ plot for the fast (a) and slow (b) modes for $N 338$.

for the higher q region, a discrepancy was observed in both cases. This has been observed for polymer micelle systems and has been thought to be duetoa bl ob scattering from themicelleshell. ${ }^{35,36}$ I $n$ thecore-shell model, uniform density in the shell was assumed. This is not a bad assumption for a small q region. However, in a higher $q$ region, which reflects a smaller scale structure, SANS detects the scattering from individual polymer chain in the shell. In fact, as shown in Figure 3, the behavior in a higher q region is well described by the Debyefunction ${ }^{37}$ for Gaussian coil. Strictly speaking, it is difficult to bel ieve that the polymer chain with a short length and tethered on the micelle core behaves as an ideal Gaussian coil, but the excellent agreement in Figure 3 means that the main factor in this q region is blob scattering. The obtained $\mathrm{R}_{\mathrm{g} \text {,Gauss }}$ values are reasonable considering the shell thickness and larger valuefor $\mathrm{N} 496$ is consistent with thelarger $m$ value.

b. Example of NSE Raw Data. Figure 4 shows a typical example of raw data of an NSE experiment. This is for polymer N496 (5 wt \%) at $q=0.06 \AA^{-1}$ at $21{ }^{\circ} \mathrm{C}$ condition. By fitting the function below,

$$
\begin{array}{r}
y=M_{1} \exp \left[-C_{1}\left(x-M_{2}\right)^{2}\right] \cos \left[C_{2}\left(x-M_{2}\right)\right]+M_{3} \\
\left(C_{1}, C_{2} ; \text { constant }\right)
\end{array}
$$

we determined the echo center $\left(\mathrm{M}_{2}\right)$ and the amplitude of echo signal $\left(M_{1} / M_{3}\left(=P_{n s e}\right)\right)$. c. Time Correlation Function for N496. Figure 5 shows the time correlation function obtained by NSE experiments $\left(P_{\text {nse }}\right)$ for $\mathrm{N} 496$ in a $5 \% \mathrm{D}_{2} \mathrm{O}$ solution at various scattering vectors $q$. At all angles studied here, this function decayed monotonically with increasing decay time (F ourier time, $\tau$ ) both at $21^{\circ} \mathrm{C}$ and $45^{\circ} \mathrm{C}$. The lines in the figure show the best fit by single-exponential function. Theagreement is not unsati sfactory, but for thedata with a largeq, a distinct disagreement between data and fitting curve can be seen in large $F_{\text {time }}$ regions. From this fitting result, the decay rate $\Gamma$ was calculated by utilization of the following equation;

$$
P_{\text {nse }}(q, \tau)=\exp (-\Gamma \tau)
$$

If we assume a translational diffusion dynamics, the translational diffusion coefficient $\mathrm{D}$ can becal culated from $\Gamma$ by

$$
\Gamma=\mathrm{Dq}^{2}
$$

This equation predicts that the $\Gamma$ vs $q^{2}$ plot should be a straight line passing through the origin if only a

(35) Richter, D.; Schneiders, D.; Monkenbusch, M.; Willner, L.; Fetters, L. J .; Huang, J. S.; Lin, M.; Mortensen, K.; Farago, B. Macromolecules 1997, 30, 1053.

(36) Pedersen, J . S.; Gerstenberg, M. C. Macromolecules 1996, 29 1363.

(37) Debye, P. J . Phys. Colloid Chem. 1947, 51, 18. 


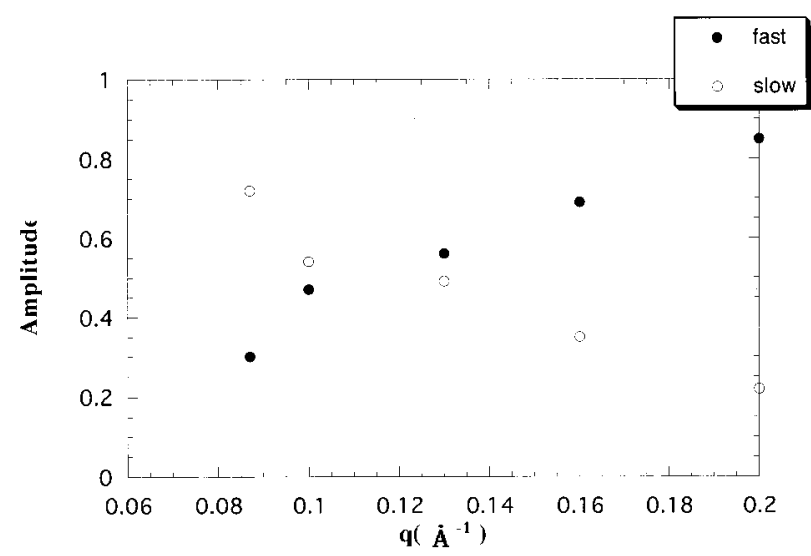

Figure 12. Theq dependence of theamplitudes of the fast and slow modes for N338.

translational diffusion dynamics exists and is detected by NSE. This plot is shown in Figure6. As expected, this plot did not show the excellent straight line passing through the origin. This should be due to the discrepancy at a large $\tau$ for large q values. Since the profiles for small q regions werewell reproduced by single-exponential fitting, in Figure 6, we tried to draw a straight line from the origin by using only three points at a small q. From its slope, the diffusion coefficient $\mathrm{D}$ was evaluated to be 2.93 $\times 10^{-7}$ and $5.64 \times 10^{-7} \mathrm{~cm}^{2} / \mathrm{s}$ at $21^{\circ} \mathrm{C}$ and $44{ }^{\circ} \mathrm{C}$, respectively. Taking the temperature change of viscosity of the solvent $\left(D_{2} O\right)$ into account, these two diffusion coefficients give us a hydrodynamic radius $\left(R_{h}\right)$ of about $68 \AA$ at both temperatures. The absence of a change in micellesizewith temperatureis compatiblewith theSANS result shown in Figure 2 . The slightly larger $R_{h}$ value than $R_{S}$ is quite reasonable if the hydrodynamic effect is taken into account. A slightly larger $R_{h}$ value than $R_{g}$ is reasonable if we consider the relations between the real geometrical size and $R_{g}$ as described previously.

Because the single-exponential fitting results were not satisfactory, we performed double-exponential fitting using the following function.

$$
P_{\text {nse }}=A_{\text {fast }} \exp \left(-\Gamma_{\text {fast }} \tau\right)+A_{\text {slow }} \exp \left(-\Gamma_{\text {slow }} \tau\right)
$$

Figure 7, a and bshows theresults of double-exponential fitting for the data in Figure 5. Obviously, thereis a better agreement between theobserved profileand fitting curve.

The $\Gamma$ vs $\mathrm{q}^{2}$ plots obtained by doubl e-exponential fitting areshown in Figure 8. Therewas a good linearity for both the fast and slow modes although there was a slight difference in the fast mode for the data with a smaller $\mathrm{q}$ value where the contribution of the fast mode was very small (see Figure 9 below). At $21^{\circ} \mathrm{C}$, these slopes gave $D_{\text {fast }}$ and $D_{\text {slow }}$ values of $1.4 \times 10^{-6}$ and $2.7 \times 10^{-7} \mathrm{~cm}^{2} / \mathrm{s}$, which correspond to $R_{h}$ fast $=15 \AA$ and $R_{h}$ slow $=66 \AA$, respectively, and at $44{ }^{\circ} \mathrm{C}, \mathrm{D}_{\text {fast }}$ and $\mathrm{D}_{\text {slow }}$ values of $1.9 \times$ $10^{-6}$ and $4.8 \times 10^{-7} \mathrm{~cm}^{2} / \mathrm{s}$, which correspond to $R_{\mathrm{h} \text { fast }}=$ $21 \AA$ and $R_{\text {h slow }}=72 \AA$, respectively. Although the time correlation functions in Figures 5 and 7 are somewhat scattered, thesystematical tendency in Figure 8 indicates the validity of our fitting procedure for these functions.

Figure 9 shows the $q$ dependence of the amplitudes for the fast and slow modes. It is obvious that in smaller q regions thesl ow mode is domi nant, but in larger q regions the fast mode is dominant. At about $q=0.1$, the contributions of thetwo modes are comparable. Thus, the slow mode shows the dynamics for a larger dimension and the fast mode those for a smaller dimension. The
Table 2. Comparison of the Diffusion Coefficients of Micelles in $\mathrm{D}_{2} \mathrm{O}$ Evaluated by Two Fitting Procedures

\begin{tabular}{ccccc}
\hline polymer & function & $\begin{array}{c}D_{\text {fast }} \\
\left(\times 10^{-6} \mathrm{~cm}^{2} / \mathrm{s}\right)\end{array}$ & $\begin{array}{c}D_{\text {slow }} \\
\left(\times 10^{-7} \mathrm{~cm}^{2} / \mathrm{s}\right)\end{array}$ \\
\hline N496 & $1^{\mathrm{a}}$ & 1.4 & $2.7^{\mathrm{b}}$ & at $21^{\circ} \mathrm{C}$ \\
& $2^{\mathrm{c}}$ & 1.7 & $2.6^{\mathrm{b}}$ & \\
& 1 & 1.9 & $4.5^{\mathrm{b}}$ & at $44^{\circ} \mathrm{C}$ \\
N338 & 2 & 2.4 & $4.5^{\mathrm{b}}$ & \\
& 1 & 1.4 & $1.9^{\mathrm{d}}$ & \\
& 2 & 1.0 & $2.0^{\mathrm{d}}$ &
\end{tabular}

a Function 1: $P_{\text {nse }}=A_{\text {fast }} \exp \left(-\Gamma_{\text {fast }} \tau\right)+A_{\text {slow }} \exp \left(-\Gamma_{\text {slow }} \tau\right)$. b Obtained by DLS at smallest $\mathrm{q}$ and fixed in fitting procedure. c Function 2: $P_{\text {nse }}=\exp \left(-\Gamma_{\text {slow }} \tau\right)\left\{\left(1-A_{\text {fast }}\right)+A_{\text {fast }} \exp \left(-\Gamma_{\text {fast }} \tau\right)\right\}$. d Obtained by NSE at smallest $q$ and fixed in fitting procedure.

(a)
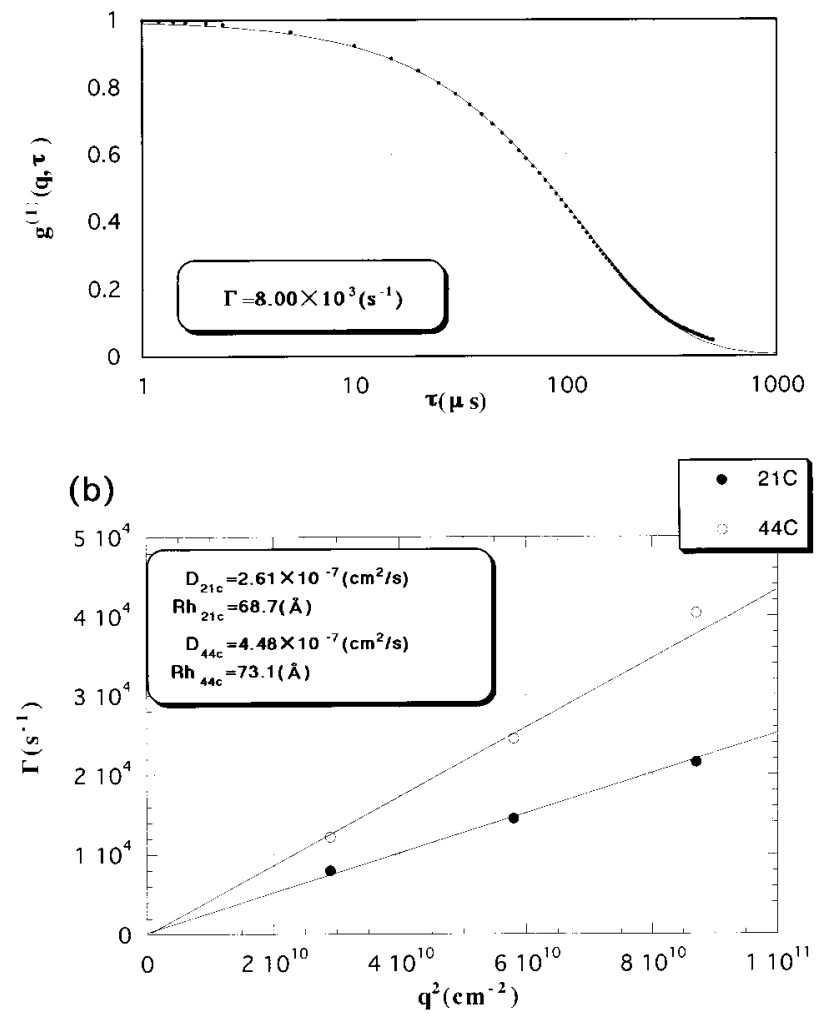

Figure 13. (a) Thetimecorrel ation function for $\mathrm{N} 496$ mi celles in aqueous solution (5\%) evaluated by DLS. Thelines show the best fit by single-exponential fitting at $21^{\circ} \mathrm{C}$, scattering angle of $60^{\circ}$; (b) $\Gamma$ vs $q^{2}$ plot.

systematical tendency in Figure 9 also supports the validity of our analysis here.

d. Time Correlation Function for N338. Figure 10 shows the time correlation function for N338 in a $5 \% D_{2} \mathrm{O}$ solution at various q conditions. Because the single exponential fitting did not show satisfactory agreement, as for N496, only the double-exponential fitting results are shown in this figure. The agreement is excellent. The tendency observed for N338 was similar to that for N 496. The linearity in Figure 11 is excellent also for the fast mode. In this experiment, the mi nimum q value was 0.06 , which was larger than that for N 496, the contribution of the fast mode is al ready large at this minimum q value. Hence, the data could be fitted with a high accuracy for all $q$ values. Figure 12 shows the $q$ dependence of the amplitudes for the fast and slow modes. As for N 496, the fast mode is dominant in higher q regions whereas the sl ow mode is dominant in lower q regions. The crossover point was al so approximately $q=0.11$. A similar tendency in Figures 8 and 9 was also observed in Figures 11 and 
(a) $21^{\circ} \mathrm{C}$

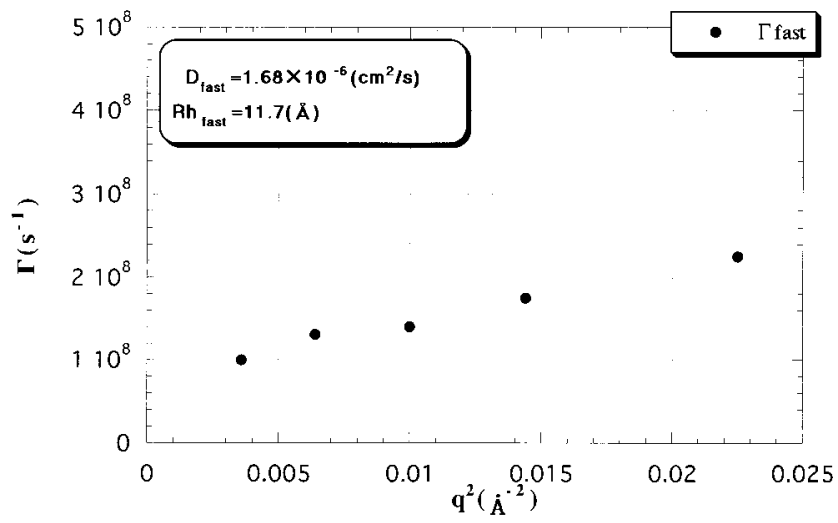

(c) $21^{\circ} \mathrm{C}$

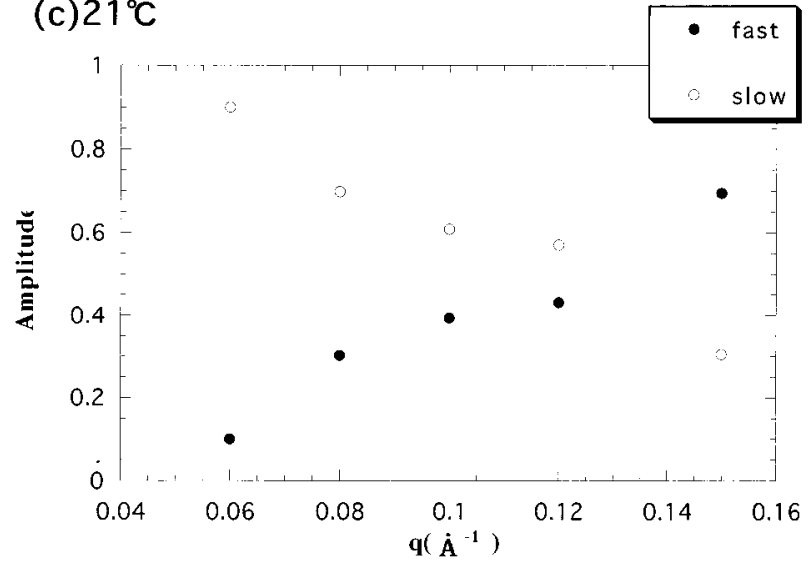

(b) $44^{\circ} \mathrm{C}$

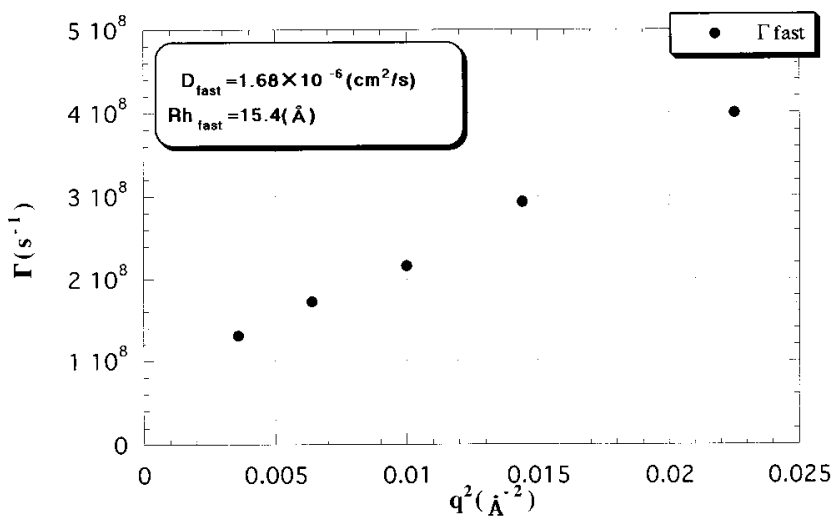

(d) $44^{\circ} \mathrm{C}$

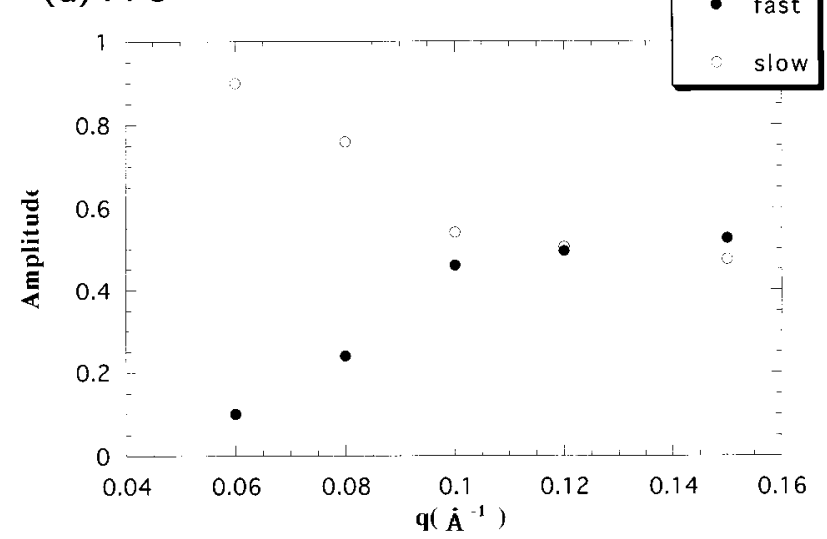

Figure 14. Fitting results of the $P_{\text {nse }}$ for $N 496$ by the function $\exp \left(-\Gamma_{\text {fast }} \tau\right)\left\{(1-a)+a \exp \left(-\Gamma_{\text {slow }} \tau\right)\right.$. (a, b) $\Gamma$ vs $q^{2}$ pl ot for the fast mode, and $(c, d)$ the $q$ dependence of amplitudes for the fast and slow modes. In this fitting, the diffusion coefficient for the slow

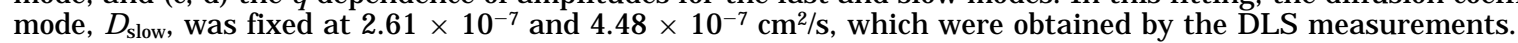

12 for the N338 sample measured by NSE instrument at $J$ ülich, which supports again the validity of our analysis.

The dynamic modes evaluated by NSE for these two polymer micelles are summarized in Table 2.

e. The Origin of the Fast and Slow Modes. The $q$ positions of NSE experiments are shown by the arrows in Figures 2 and 3. Measurement was not possiblein smaller $q$ regions because of the effect of the direct beam and in larger q regions because of insufficient scattering intensity. The SANS profiles imply that the angular range for the NSE experiment lays on theborder of theso-called Guinier regions ${ }^{33}$ and Porod region. ${ }^{38}$ Hence, it is reasonable to assume that the dynamic behavior both for the whole micelleand internal structurecan bedetected at thesame time in these q ranges. From the comparison between $R_{h}$ values by NSE and micelle size estimated by SANS and SAXS, the slow mode, $D_{\text {slow }}$ and $R_{h}$ slow, should be for the translational diffusion of the polymer micelle itself. To confirm the validity of this conclusion, we performed DLS experiments for the N496 sample. The results (time correlation function) are shown in Figure 13. This time correlation function was well reproduced by cumulant fitting, and the slope of $\Gamma$ vs $q^{2}$ plot gave us $R_{h}$ values of $68 \AA$ and $73 \AA$ at $21^{\circ} \mathrm{C}$ and $44^{\circ} \mathrm{C}$, respectively, which are in excellent agreement with the NSE value for the slow mode $\left(R_{h, \text { slow }}=66 \AA\right.$ by NSE at $\left.21^{\circ} \mathrm{C}\right)$. It is reasonablethat DLS can detect only the translational diffusion of the micelle (slow mode in NSE) because DLS covers only a very small q range that corresponds to the fluctuation of large dimensions; the dynamics in a small scale, such as

(38) Porod, G. Kolloid.-Z. 1951, 124, 83. the internal motion of a polymer micelle, cannot be observed by DLS. Hence, the slow mode in NSE data corresponds to the translational diffusion of the whole micelle.

Figures 9 and 12 clearly show that the amplitude, that is, the contribution, of the slow mode decreased with increasing q, whereas, that of the fast mode increased. This tendency also supports our conclusion above for the origin of the fast and slow modes. With increasing $q$, the scattering detects the structure and fluctuation of a smaller dimension.

At this moment, we cannot justify the linearity of the fast mode shown in Figures 8 and 11 . I f this is an internal dynamic mode in the polymer micelle, this mode is not translational dynamics. Hence, in these plots thefast mode need not give a straight line passing through the origin . Frankly speaking, the excellent linearity observed in Figure 11 was unexpected. Themost suitableexplanation for the origin of the fast mode might be the "corona" dynamics of the polymer micelle. As mentioned in the introduction, several investigators have drawn this conclusion for the nonaqueous system. Some theoretical approaches have also been taken. ${ }^{26}$ One possible factor might bethe existence of uni mers in the system. As in the low molecular weight mi cellar system, al so in the polymer micelle system there are unimers with a concentration equal to the critical micelle concentration (cmc). Because unimers show translational diffusion, thereis a possibility that NSE detected this motion of unimers. However, the concentration of unimers should bevery low. Our polymers have a $\mathrm{cmc}$ value of about $0.02 \mathrm{wt} \%$; lower by 2 orders of magnitude. In addition, by the basic scattering theory, 
(a)
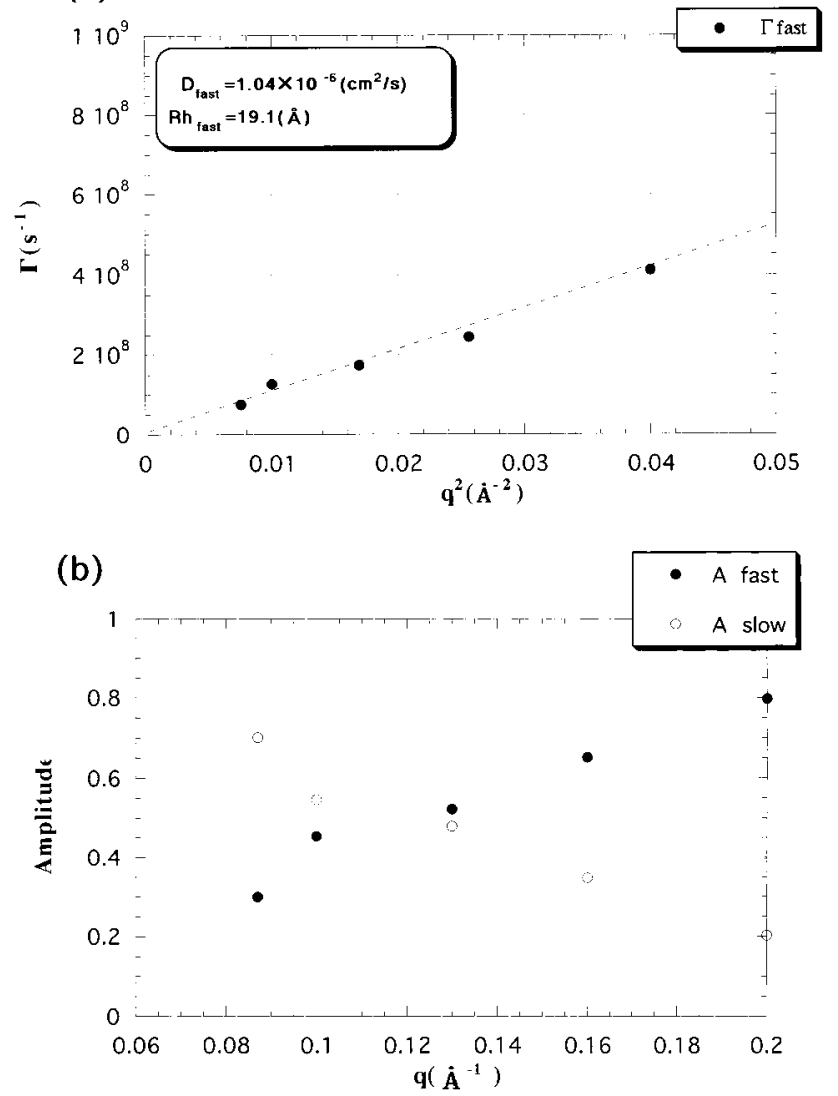

Figure 15. Fitting results of the $\mathrm{P}_{\text {nse }}$ for $\mathrm{N} 338$ by the function $\exp \left(-\Gamma_{\text {fast }} \tau\right)\left\{(1-a)+a \exp \left(-\Gamma_{\text {slow }} \tau\right)\right\}$. (a) $\Gamma$ vs $q^{2}$ plot for the fast mode, and (b) the $q$ dependence of amplitudes for the fast and slow modes. In this fitting, the diffusion coefficient for theslow mode, $D_{\text {slow, }}$ was fixed at $2.03 \times 10^{-7} \mathrm{~cm}^{2} / \mathrm{s}$, which was obtained from the NSE data at the lowest q value.

the scattering intensity proportional to the square of the volume of thescatterer ${ }^{33,34}$ Hence, thescattering intensity from unimers is expected to be very weak and not a significant contributor to the NSE data here. However, this possibility should be examined in more detail in the future because the linearity in Figure 11 a is excellent.

$\mathbf{f}$. Further Analysis of $\mathbf{P}_{\text {nse. }}$ For the analysis of time correlation function, such as $\mathrm{g}_{(1, \tau)}^{(1)}$ by DLS and $P_{\text {nse }}$ by NSE, single-exponential fitting and the double-exponential fitting are common and useful techniques. In fact, we have performed the double-exponential analysis above. However, according to our conclusion above, that is, the slow mode is the translational diffusion of the whole polymer micellein water and the fast modeis theinternal model for the hairy corona (shell) of the polymer micelle, might be more appropriate to use the following functions as a fitting function for analysis,

$P_{\text {nse }}=\exp \left(-\Gamma_{\text {slow }} \tau\right)\left\{\left(1-\mathrm{A}_{\text {fast }}\right)+\mathrm{A}_{\text {fast }} \exp \left(-\Gamma_{\text {fast }} \tau\right)\right\}$

where $A_{\text {slow }}=1-A_{\text {fast }}$. This concept comes from the idea that the internal corona mode is not independent of the translational diffusion of the whole polymer micelle: the hairy corona, which shows the internal fast motion, is fixed on the polymer micelle which is moving at a decay rate of $\Gamma_{\text {slow. }}$. Hence the fast mode is "convoluted" to the slow modeand one of its model functions is eq 4 . Wefitted $P_{\text {nse }}$ by eq 4 with fixed $D_{\text {slow }}$ values, hence $\Gamma_{\text {slow: }}$ one value is that obtained by NSE at the smallest q value, which might reflect only the slow mode, and the other is that obtained by DLS. The former method was applied to N338 data and the latter to $\mathrm{N} 496$ data. The results are shown in Figures 14 and 15. Although almost no significant improvement can be found for N486, slightly "better" linearity in the $\Gamma \mathrm{vsq}^{2}$ plot is observed for N 338. A similar $q$ dependence of the amplitude was also detected. There seems to be no serious difference in the choice of $D_{\text {slow }}$ value. The diffusi on coefficients obtained by this method and the double-exponential method are summarized in Table 2.

Although we believe that the origin of the fast mode is the corona dynamics, more detail ed analysis is necessary to clarify this point completely. Further analysis for time correlation function, such as fitting by stretched exponential, is one possibility. A careful estimation of the dependence of $\Gamma$ on $q$ is also an important factor. A theoretical approach, such as that which Monkenbusch et al. applied, ${ }^{26}$ might be also interesting because it has not been applied and tested for aqueous systems.

\section{Conclusions}

By systematicNSE experiments, wefound thepresence of two dynamic modes, the fast and the slow modes, for amphiphilic diblock copolymer micelles in aqueous solutions. At smaller q values, the slow mode was the dominant, wher eas at larger q values, the fast mode was dominant. The diffusion coefficient $D$ for the slow mode of the $\mathrm{N} 496$ sample was about $2.7 \times 10^{-7} \mathrm{~cm}^{2} / \mathrm{s}$ at $21^{\circ} \mathrm{C}$, which gavea hydrodynami cradius of about $70 \AA$. Because SANS, SAXS, and DL S gaveal most thesamegeometrical size, this slow mode is consi dered to be the translational motion of the whole micelle. At $44^{\circ} \mathrm{C}$, the slow mode in NSE gave the same size of micelle, which is in good agreement with the results obtained by SANS and DLS. Similar results were obtained for the N338 sample. The fast mode, which is faster than the slow mode by 1 order of magnitude, is thought to be the dynamic mode of the hydrophilic shell (corona). M ore detailed analyses, such as a comparison with theoretical prediction, is now underway. Here, we demonstrated that NSE is a very powerful tool to study dynamics that cannot be covered by theDLS techniquefor spatial dimension and timeorder.

Acknowledgment. This work was financially supported by grants-in-aid for Scientific Research by the Ministry of Education, Sports, and Culture of J apan (A09305062 and 00086208) to whom our sinceregratitude is due. The measurements at J ülich were supported by a Grant for J oint Research Project under the J apaneseGerman Cooperative Science Promotion Program from bothJ apan Society for Promotion of Scienceand Deutsche Forschungsgemeinschaft. NSE experiments at Tokai was accepted as Proposal N o. 98-104. H.M., M.N., and H.E. woul d liketo express their sincerethanks to themembers of I nstitut für Festkorperforschngs for their kind support during their stay at J ülich and especially for R.Schäzler for hiskind technical assistancein theNSE measurements at J ülich.

LA9915421 